\title{
Avrupa Kültür Başkentleri, Kütüphaneleri ve İstanbul 2010
}

\author{
European Capitals of Culture, Libraries and Istanbul 2010
}

Serdar KATIPOĞLU*

\begin{abstract}
Öz
Bu yazıda, Avrupa Kültür Başkentlerinin oluşumu, kütüphanelerin bir kültür sektörü olarak yeniden tanımlanması, kültür başkentlerinin kendi süreçleri içinde kütüphanelerle ilgili geliştirdikleri projeler ve uygulamalar anlatılmıştır. Bu bağlamda, 2010 yılında Avrupa Kültür Başkenti olacak Istanbul'un, kütüphaneler ile ilgili politikasının belirlemesi ve uygulamaya geçilmesinin gerekliliği vurgulanmıştır.
\end{abstract}

Anahtar sözcükler: Kültür başkentleri, Kütüphaneler, Avrupa, Türkiye

\begin{abstract}
In this article, the formation of European Capital of Culture, redefinition of libraries as a cultural realm; projects, case studies and applications developed by Capital(s) of Culture are explained and described. In this context, the significance of Istanbul as the European Capital of Culture in 2010; the certain necessity of developing Istanbul's urban policies on libraries and the importance of starting an applied program of actions about these library policies are emphasized.
\end{abstract}

Keywords: Capitals of culture, Libraries, Europe, Turkey

\section{Giriş}

Pek çok oluşum, kurum gibi biz kütüphaneciler de İstanbul'un Avrupa Kültür Başkenti olma sürecini, duyurulduğu günden itibaren izlemeye başladık. 2010 yılına sayılı günlerin kalması ve programda yer alan İstanbul Kütüphanesi'nin bir an önce kurulmasını kutlayacağımız 45. Kütüphane Haftası'nda bir kez daha hatırlatmak istedik. İstanbul'un kültür başkenti olma sürecini kütüphaneler açısından daha iyi anlamak, yorumlamak ve sonuçlandırmak için önce Avrupa'da kültür başkenti olmuş kentlerin, kütüphaneler ile olan ilişkilerine ve izledikleri politikalara bakalım.

* Kütüphane ve E-Kaynaklar Direktörü; İstanbul Bilgi Üniversitesi Kütüphanesi, İstanbul. (serdar@bilgi. edu.tr) 


\section{Avrupa Kültür Başkentlerinin Oluşumu}

Avrupa Kültür Başkenti farklı bir tanımla olsa da ilk kez Yunanistan Kültür Bakanı Melina Mercouri tarafından önerilmiş ve bir jest olarak bu sıfat 1985 yılında Atina'ya verilerek süreç başlatılmıştır. Zaman içinde kültür başkenti olmak, o kente sadece statü vermek ya da kültürel aktivite yapmak anlamından kurtulup, kentin kalıcı unsurlarla gelişmesine katkıda bulunmak anlamına dönüşmüştür.

\section{Kültür Başkentleri ve Kütüphaneler}

1997 yılında, Selanik’te kültür başkenti için kültürel amaçlı birçok bina inşa edilmiştir. Bunlar içinde en dikkati çeken ise yeni kütüphane binasıdır. Selanik Uluslararası Kütüphanesi adı ile 1997 yılının Mart ayında açılan bu kütüphane takip eden yıllarda diğer kütüphanelerle birleştirilerek daha da geliştirilmiştir. Bu kütüphane günümüzde akademik nitelikte, genel eğitimle bütünleşmiş ve halka açık bir kütüphane olarak tanımlanmakta ve işlevini sürdürmektedir.

1985’ten 2000 yılına kadar Avrupa Birliği (AB) üyesi olan ülkelerden kültür başkentleri seçilirken, yeni binyılın (milenyum) başlamasıyla Avrupa Kültür Başkenti unvanı hem birden fazla kente, hem de AB Adayı olan ülkelerin kentlerine de verilmeye başlanmıştır. Böylece 2000 yılında kültür başkenti sayısı dokuza çıkmıştır. Bu dokuz kent içinde bulunan Avignon (Fransa), Cracow (Polonya), Helsinki (Finlandiya) ve Santiago del Compostela (İspanya) kentleri kütüphane binası projeleriyle işbirliğine gitmişlerdir. Yalnız kütüphane binası projesiyle yetinmeyip kütüphanelerde yazarlarla yapılacak oturumlar, edebiyat projeleri ve okuma uygulamalarıyla ilgili programları da belirleyici unsur olarak sunmuşlardır (Dewe, 2006).

2005 yılı Kültür Başkenti Cork (İrlanda) kentinde Tory Top’ta yeni bir kütüphane açılmış, Wilton Shopping Centre Kütüphanesi de yenilenmiş ve her iki kütüphane de çağdaş bir yönetim anlayışıyla hizmet vermeye başlamıştır. Kütüphanelerin dermeleri güncel kaynaklarla zenginleştirerek kentlilerin kullanımına sunulmuştur. Kent yönetimi ve yerel yönetim birimleri ortak bir bütçeyle bu projeleri finanse etmişlerdir (Corck, 2005 Archive, 2009).

2007 yılı Kültür Başkenti Sibiu (Romanya) kenti, resmi internet sayfasında olmamasına karşın bir gazete haberinde Astra Kütüphanesi binasının açılışını bildirilmiştir. Aynı haberde bu faaliyetin Romanya'nın AB'ye kültürel katkısının önemli bir göstergesi olduğuna da dikkat çekilmiştir (International Herald Tribune, 2008).

2008 yılı için Avrupa Kültür Başkentleri olarak seçilen Stavanger (Norveç) ve Liverpool (İngiltere) sundukları ve gerçekleştirdikleri programlarıyla kültürel işlevlerini kütüphanecilik açısından başarılı bir şekilde yerine getirmiştir. Stavanger'de 1987 yılından beri bir kültür ve toplantı arenası olan Stavanger Kültür Merkezi, Kültür Başkenti sürecinde programların yoğunlaştığı bir yer olmuştur. Bu merkez, bünyesinde 8 sinema, birer kütüphane ve sanat galerisi ile toplantı salonlarını barındırmasının yanı sıra kafe ve dükkânlarıyla da bireyin kültür ve toplum ile buluştuğu bir sosyal alışveriş, bir iletişim ortamı olarak işlevini sürdürmektedir. 
Kültür Merkezinde ise, esas vurgulanan bölüm kütüphanedir. Stavanger Kütüphanesinin halen ülkenin en yeni ve en büyük kütüphanesi olduğunu da burada belirtelim.

Liverpool (İngiltere)'da 2008 yılı Kültür Başkenti olarak aynı yıl Liverpool Merkez Kütüphanesi açılmıştır. Ayrıca, son beş yıl içinde Liverpool'daki kütüphanelerin yarısı onarımdan geçirilmiş ya da yerleri değiştirilmiştir. Özellikle belirtilen bir özellik ise, kütüphane kullanıcılarının 7'den 70'e yerine, yedi aylıktan 101 yaşına şeklinde tanımlanmasıdır. Çünkü kütüphane yetkilileri en genç kullanıcılarının yedi aylık, en yaşlı olanın ise 101 yaşında olduğunu belirtmektedir.

2008 yılı kültür başkenti seçimi için 8 kent başvuruda bulunmuştur,. Aday kentlerin başvuru taslaklarında kütüphaneler, yapacak önemli yatırımlar olarak gösterilmiştir. Örneğin, Birmingham Merkez Kütüphanesinin yeni bir alanda yeniden kurulacağı; Bristol'da ise dört yeni kütüphanenin açılacağı ve Newcastle'da yeni bir merkez kütüphane için yeterli bütçe olduğu belirtilmiştir.

Bir diğer örnek, 2009 Kültür başkenti Linz (Avusturya) ise bambaşka bir programla karşımıza çıkmıştır: "Yüz Dilin Kütüphanesi”. Bu program Linz’te yaşayan göçmen veya kentli ve ana dili Almanca olmayan kişiler için tasarlanmıştır. Bu programa kitap bağışlayıcı veya ödünç alıcı gibi iki pozisyonda katılan kişiler, kendi ana dillerindeki kitap veya benzer yazılı kaynakları kütüphaneye bağışlamaktadır. Böylece, en az 100 farklı dilde 1000 kitaptan oluşan bir kitaplık kurulması düşünülmektedir. Bu program için kullanılacak kütüphane, fiziksel olarak konteynırdan oluşacak ve merkez kütüphanenin önüne yerleştirilecektir. Linz'in böylece kültür başkenti döneminde özel nitelikte bir kütüphanesi oluşmuştur (Linz2009, 2009).

\section{Palmer Raporu}

Avrupa Kültür Başkentlerinin manifestosu sayılabilecek Palmer/Rae Associates'in hazırladığı raporu (Report on European Cities and Capitals of Culture) yani Palmer Report'u incelediğimizde, kütüphanelerle ilgili yeni anlamlar, görevler ve roller görmekteyiz. Raporda bulduğumuz bazı örneklere göz atalım.

Stockholm 1998'de, yerel yönetim kentte çalışan insanları kültür başkenti programı için eğitmiştir. Böylece hem yeni iş olanakları, hem de geniş bir katılımı sağlanmıştır. Kütüphaneciler de enformasyon uzmanı olarak toplumu bilgilendirme sürecinde aktif rol almışlardır. Helsinki'de yerel yönetim tarafından Avrupa Kültür Başkenti projeleri hakkında bilgi vermek ve bu projeler ile ilgili görüş almak için kütüphanelere fikir kutuları diye adlandırılabilecek "ideas boxes" lar koyulmuştur Böylece kütüphaneler aracılığıyla toplumun aktif olarak kültür başkenti sürecine katılımının sağlanması amaçlanmıştır.

Raporda dikkati çeken bir diğer nokta, "kültürel sektör" tanımının kullanılmasıdır. Tiyatro, dans, opera, görsel sanatlar, film, edebiyat, mimarlık, tasarım, moda, dijital sanat, klasik müzik, pop, caz ve elektronik müziğin yanı sıra arşivler ve kütüphaneler de bu tanım ve sınıflama içinde yer almaktadır. Bunun ilk uygulamalarını Luxembourg 1995'de, Cophenhagen 1996'da görüyoruz. Kültürel sektör tanımlarına 1996 yılından bugüne, 
oluşan yeni kültürel sektörler de eklenmeye devam etmektedir (Palmer/Rae Associates International Cultural Advisors, 2004, s.118).

\section{Ortak Projeler}

2000'li yıllarda ise, kültür başkentleri, ortak projelere ve işbirliğine dönük çalışmalara yönelmeye başlamıştır. Ortak projelerde mimarlık, dans, tasarım, film, yeni medya, görsel tasarımın yanı sıra arşiv ve kütüphaneleri de görüyoruz. Örneğin: Helsinki 2000, Prag 2000, Bruges 2002.

Bergen 2000'de ise, karşımıza çıkan "European Cooperation" projenin altında arşiv kitapları ve bilgi ağı programını görmekteyiz. Bu programda kütüphanelerdeki bilgi kaynaklarıyla Norveç, İzlanda, Çek, Finlandiya, İspanya, İtalya arasında bir bilgi ağı oluşturulmuştur. Bu bilgi ağı yazar değişim programlarıyla da desteklenmiştir.

\section{Altyapı Projeleri}

Yazımızın başında belirttiğimiz gibi, kültür başkenti olmak süreç içinde kültürel kalıcı yatırımların yapıldığı bir kent olmaya dönüşümü de sağlamaktadır.

Kopenhag 1996'da Danimarka Kültür Bakanlığı, Milli Kütüphane'yi içinde barındıran yeni bir kültür merkezi yapımını gündeme almıştır.

2000 yılı Kültür Başkenti Bolonya (İtalya)'da Sala Borsa Kütüphane binasını restore etmiştir. 2000 yılında resmi olarak açılan kütüphane 2001 yılında halka hizmet vermeye başlamıştır (Palmer/Rae Associates International Cultural Advisors, 2004, s.144).

2001 yılı Kültür Başkenti Porto (Portekiz)'da ise “Almeida Garrett da Vitoria Kütüphanesi Ekim 2000 de içi ve dışı mekânları yenilenerek tekrar açılmıştır (Palmer/Rae Associates International Cultural Advisors, 2004, s.254).

Hemen hemen bütün kültür başkentleri programlarında tarihi binalar yenilenmekte ve kültürel miras niteliği olan yapılar gözden geçirilmektedir. Uygun nitelikteki eski binalar ise müze, galeri, kütüphane ve performans merkezlerine dönüştürülmektedir.

\section{İstanbul 2010}

Kütüphaneler ile ilgili bilgi almak için İstanbul 2010'un internet sayfasına baktığımızda, "Murad Molla Kütüphanesi" restorasyonu ile ilgili bir bilgi notunu görmekteyiz. İstanbul Kütüphanesi için arama yaptığımızda ise "Rami Kışlası"nın halk kütüphanesi ve kültür merkezi olarak geliştirilmek üzere İstanbul Büyükşehir Belediyesi'ne devrediliyor” haberini bulabiliriz. Hâlbuki 2008 Mart ayında, İstanbul 2010'un internet sayfasında İstanbul Kütüphanesi ile ilgili çok daha kapsamlı bilgiler yer almaktaydı. Böylece kültür başkenti olarak İstanbul, kütüphaneler başkenti olma yolunda somut bir adım atmış olduğunu gösteriyordu. Hatırlamakta yarar var, Avrupa Komisyonu; İstanbul, Pecs (Macaristan), Essen-Ruhr (Almanya) kentlerini de 2010 yılı için Avrupa Kültür Başkentleri olarak ilan etmiş ve üç kent bu amaçla sanat ve kültür ağırlıklı plan ve projelerini hayata geçirmeye başlamışlardır. 
Örneğin, Essen 2010 için Ruhrbölgesindekitümüniversite, halk, özelkonu kütüphaneleri bir bilgi ağında birleştirilmektedir. Tarihi değerleri olan tüm kitap ve dokümanlar, bir kültürel miras kaygısıyla bu bilgi ağında kamuoyuna ve topluma dijital ortamda sunulmaktadır. Ayrıca Essen 2010 için diğer kardeş kültür başkentlerle işbirliği yapılacağı da belirtilmektedir (Mamecke, 2008).

Pecs 2010 için ana projelerden biri olarak "Güney Tuna Bölge Kütüphanesi ve Bilgi Merkezi” adıyla büyük bir kütüphane binası yapılmaktadır. Bu yapı için bir mimarlık yarışması açılmıştır ve 2007 yılında sonuçlandırıımıştır (Toller, 2008).

Sonuç olarak İstanbul 2010 adına süre giderek daralmaktadır. Hatta 2010'nun diğer kültür başkenti olan diğer iki kardeş kent ile karşılaştırıldığında geç bile kalınmıştır.

Yine de, İstanbul 2010 Avrupa Kültür Başkenti Kanunu'nda belirtilen İstanbul Kütüphane ve Kültür Merkezi'nin yapımına ivedilikle başlanmalıdır. Ancak bu bir inşaat süreci olmamalı ve böyle algılanmamalıdır. Öncelikle ulusal düzeyde bir mimarlık yarışması açılmalı ve mimari açıdan kendini aşan bir yapı olmalıdır. Aynı zamanda bu yarışma ile ilgili süreç entelektüel bir ortama dönüştürülmeli ve toplumla paylaşılmalıdır. Kütüphanenin temelinin atılması için en son şans 2010 yılı olacaktır.

Toplumsal amaçlı bir sosyal sorumluluk projesi olarak nitelenebilecek bu kütüphane, İstanbul'un en önemli kültür belleği simgelerinden biri olmalıdır. Çünkü o İstanbul'un belleği ve geleceğidir.

\section{Avrupa Kültür Başkentleri}

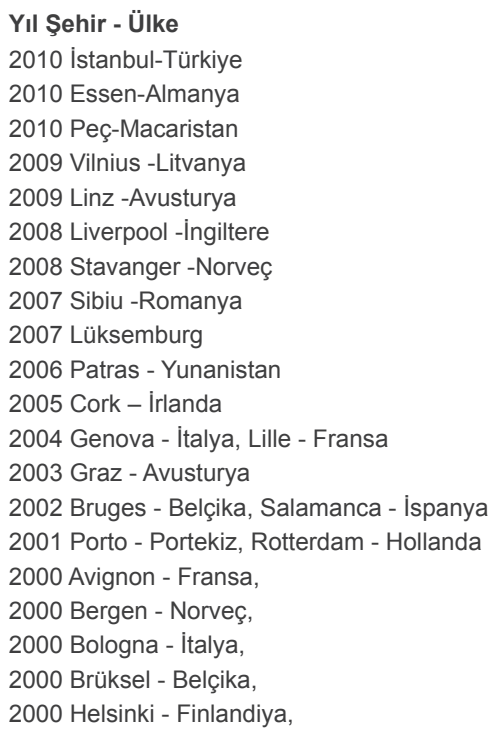

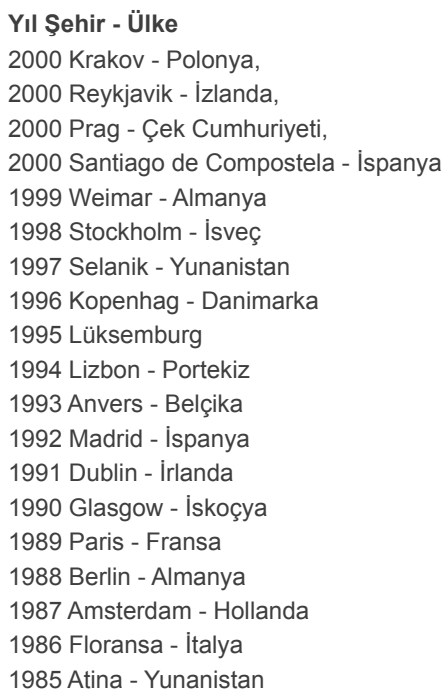




\section{Kaynakça}

Cork 2005 Archive. (2009). 1 Eylül 2009 tarihinde http://www.cork2005.ie/about2005/ capitalprojects.shtml adresinden erişildi.

Dewe, M. (2006). Planning public library buildings: Concepts and issues for the librarian. Aldershot: Ashgate.

Toller, L. (2008). European Capital of Culture-Pécs, 2010: Borderlesscity. Pécs: Pécs 2010 Application Centre, Europe Centre Pbc. 25 Temmuz 2009 tarihinde http://195.228.152.115/ public/upload/file/dokumentumok/nyilvanos/pecs2010_english.pdf adresinden erişildi.

International Herald Tribune. (2008).14 Mart 2008 tarihinde http://www.iht.com/articles/ ap/2007/01/01/europe/EU_GEN_Romania_Culture_Capital.php adresinden erişildi.

Mamecke, I. (2008). Libraries on their way to the European Capital of Culture 2010. 31 Ağustos 2009 tarihinde http://library.bilgi.edu.tr adresinden erişildi.

Linz2009. (2009). The library of a hundred languages. 31 Ağustos 2009 tarihinde http://www. linz09.at/en/projekt-2106467/bibliothek_der_100_sprachen.html adresinden erişildi

Palmer/Rae Associates International Cultural Advisors. (2004). European cities and capitals of culture Part I, II. 30 Ağustos 2009 tarihinde http://www.palmer-rae.com adresinden erişildi. 